\title{
MODELO DE PRECIFICAÇÃO DE ATIVOS DE CAPITAL: UM ESTUDO DE CASO NO SETOR DE FRIGORÍFICOS
}

CAPITAL ASSET PRICING MODEL: A CASE STUDY ON MEAT SECTOR

\author{
Tácito Augusto Farias ${ }^{1}$ \\ Luiz Eduardo Nascimento Figueiredo ${ }^{2}$ \\ Fabio Rodrigues de Moura ${ }^{3}$
}

\section{RESUMO}

O objetivo do artigo é a aplicação do modelo de precificação de ativos conhecido na literatura economia financeira como CAPITAL ASSET PRICING MODEL - MODELO DE PRECIFICAÇÃO DE ATIVOS DE CAPITAL, utilizando como ferramentas os balanços patrimoniais das empresas selecionadas JBS S.A. e BRF - BRASIL FOODS S.A., no período relativo ao ano de 2009 e 2010. Resultado fundamental: ambas as empresas no período em estudo apresentaram um beta inferior a 1, ou seja, risco menor que o risco do mercado.

\section{ABSTRACT}

This paper aims to application of CAPITAL ASSET PRICING MODEL using as tools the accounting balances of firms in years 2009 and 2010. Fundamental result: both firms in years $2009-2010$ presented beta value less than 1, it means risk less than market risk.

JEL: A.1.

\section{INTRODUÇÃO}

O Brasil começou a se sobressair no segmento de agronegócio quando foi inserido na economia contemporânea internacional, a partir dos anos noventa. Hoje em dia, o segmento de agronegócio representa $22 \%$ do produto interno bruto brasileiro, retratando, deste modo, sua importância para a economia brasileira.

Agronegócio é um conjunto de atividades que associadas garantem a produção, a transformação, a distribuição e o consumo de produtos provenientes da agropecuária. Destaca-se a projeção dos técnicos da ESALQ/USP em que afirmam um crescimento no segmento de agronegócio em torno de $40 \%$, nos próximos 10 anos, a contar de 2010.

\footnotetext{
${ }^{1}$ Doutor em Economia pela ESALQ/USP. Professor do Departamento de Economia da Universidade Federal de Sergipe.E-mail: tacitoaugusto@yahoo.com.br

2. Doutorando em Economia pela Universidade Federal de Pernambuco. E-mail: lenfigueiredo@yahoo.com.br

3. Doutorando em Economia Aplicada pela ESALQ - USP. E-mail: fabirosmash@yahoo.com.br
} 
Os conhecimentos teóricos e aplicados, elaborados e estabelecidos nas finanças quantitativas têm sido destaque a partir dos anos 50. Ao longo deste período, especialistas se debruçaram no estudo das características e da análise de ativos individuais, bem como na constituição e escolha da carteira ótima. Foram desenvolvidas técnicas matemáticas sofisticadas para construção de modelos teóricos e ferramentas estatísticas que melhor se adequam a coleta e geração dos dados. Modelos econométricos dinâmicos e análise de séries temporais em dados de painel são os destaques.

Nosso propósito neste artigo, é a aplicação direta do modelo de precificação de ativos conhecido na literatura econômica financeira como Capital Asset Pricing Model -"Modelo de precificação de ativos de capital, desenvolvido por Sharpe(1964), Lintner (1965) e Mossin (1966). Este modelo está inspirado no Princípio da Dominância, no qual os ativos que se encontram na FRONTEIRA EFICIENTE têm vantagens sobre os outros ativos no Plano de Retornos Esperados e Risco, segundo Lencione (2005).

A aplicação está orientada para o setor de frigorífico, destacando-se duas empresas gigantes do segmento: JBS S.A. e BRF - BRASIL FOODS S.A, que são importantes na geração de emprego e renda na economia nacional. $O$ artigo está estruturado da seguinte forma: a seção 2 aponta os elementos orientados para a avaliação de ativos financeiros - valor esperado e desvio padrão; seção 3 apresenta de forma simplificada o CAPM; seção 4 faz uso dos conhecidos supracitado no segmento do frigorífico. Encerramos o artigo com comentários pertinentes aos resultados obtidos.

\section{FUNDAMENTAÇÃO TEÓRICA}

\subsection{Pensar Retorno como Variável Aleatória}

$O$ retorno financeiro, em termos gerais, pode ser entendido como o montante de ganhos ou perdas vinculados a um ativo dentro de um período específico (GITMAN, 2010). Para o investidor, o retorno está relacionado diretamente ao aumento ou à diminuição de sua riqueza, e é certo que os agentes racionais sempre buscam a sua maximização. De todo modo, é necessário tornar esse conceito mensurável, a fim de quantificar a rentabilidade de um determinado ativo.

As variáveis aleatórias (v.a.) são classificadas em discretas e contínuas. Uma v.a. é discreta quando o intervalo de valores que ela pode assumir é formado apenas por um número finito de termos, ou infinito enumerável, os quais podem ser contados utilizando-se os números inteiros. Já uma v.a. é dita contínua quando ela pode assumir qualquer valor real, dentro de um intervalo (finito ou infinito) de números reais (ZHU; PRIETULA; HSU, 1997).

Considere inicialmente que o retorno de uma determinada ação adquirida por um investidor seja uma v.a. discreta denotada por $R_{i}$, cujos valores são indicados por $r_{i}$. Sabemos que não é possível conhecer o retorno exato até sua observação, mas o investidor tem como estimativa suas 
expectativas dos prováveis retornos. Observando o comportamento da ação ao final de vários meses, o investidor conclui que, no próximo período, o seu retorno somente pode assumir um dentre os seguintes valores: $R_{i}=\{-10 \%$, $5 \%, 15 \%, 30 \%, 40 \%$. Cada um desses valores representa um determinado cenário para o investidor, que pode estar relacionado ao estado em que se encontra a economia, ou mais precisamente, ao desempenho da empresa cuja ação foi adquirida frente a fatores macro ou microeconômicos (SECURATO, 1993). Como, a depender das condições enfrentadas, cada retorno tem uma determinada possibilidade de ocorrer, o investidor formaliza a seguinte ideia quanto ao comportamento da ação:

\section{Tabela 1 - Distribuição probabilística discreta dos retornos}

\begin{tabular}{c|c|c}
\hline Cenário & Retorno $\left(\boldsymbol{R}_{\boldsymbol{i}}\right)$ & Probabilidade $\left(\boldsymbol{P}\left(\boldsymbol{R}_{\boldsymbol{i}}\right)\right)$ \\
\hline Péssimo & $-10 \%\left(r_{1}\right)$ & $10 \%\left(p\left(r_{1}\right)\right)$ \\
\hline Ruim & $-5 \%\left(r_{2}\right)$ & $25 \%\left(p\left(r_{2}\right)\right)$ \\
\hline Regular & $15 \%\left(r_{3}\right)$ & $30 \%\left(p\left(r_{3}\right)\right)$ \\
\hline Bom & $30 \%\left(r_{4}\right)$ & $25 \%\left(p\left(r_{4}\right)\right)$ \\
\hline Excelente & $40 \%\left(r_{5}\right)$ & $10 \%\left(p\left(r_{5}\right)\right)$ \\
\hline
\end{tabular}

Fonte: Elaborado pelo autor.

Observe que para cada valor que o retorno possa assumir dentro do intervalo especificado, há uma probabilidade associada. O retorno de $-5 \%$ tem $15 \%$ de probabilidade de ocorrer e isso representa um cenário ruim para 0 investidor (uma recessão econômica ou um desempenho deficiente da empresa em seu setor). Já o retorno de $40 \%$ tem $20 \%$ de probabilidade de se realizar, o que caracteriza um excelente cenário de investimento.

As probabilidades do retorno deste exemplo são definidas como probabilidades objetivas ${ }^{4}$ : é a frequência relativa com que um determinado retorno (evento) ocorre em muitas observações deste experimento não controlado (o comportamento da ação). Assim, temos que, se $t$ é a quantidade de vezes em que o retorno da ação foi observado ao final de um mês, e $t\left(R_{i}\right)$ é o número de vezes que um determinado retorno ocorre durante essas observações, a probabilidade de $R_{i}$ é dada pelo quociente $\frac{t\left(R_{i}\right)}{t}$, quando $t$ tende ao infinito:

\footnotetext{
${ }^{4}$ Segundo ASSAF NETO (2005, p. 320), "a probabilidade objetiva pode ser definida a partir de séries históricas de dados e informações, freqüências relativas observadas e experiência acumulada no passado". Por outro lado, poderíamos considerar também a probabilidade subjetiva do investidor, que "tem como base a intuição, o conhecimento, a experiência do investimento e, até mesmo, um certo grau de crença na unidade tomadora de decisão" (idem).
} 


$$
P\left(R_{i}\right)=\lim _{t \rightarrow \infty} \frac{t\left(R_{i}\right)}{t}
$$

O conjunto de valores discretos que o retorno pode assumir, juntamente com suas respectivas probabilidades de ocorrência, como mostra a tabela 1 , formam a chamada distribuição probabilística discreta dos retornos, a qual está associada a uma função distribuição de probabilidade ou função massa de probabilidade dos retornos (HOGG; MCKEAN; CRAIG, 2004). Para a v.a. discreta $R_{i}$, o valor da sua função massa de probabilidade, dada por $p\left(r_{i}\right)$, é a probabilidade de $R_{i}$ tomar um determinado valor $r_{i}$ :

$$
p\left(r_{i}\right)=P\left(R_{i}=r_{i}\right)
$$

Considerando os retornos discretos supra-elencados, o valor da função distribuição de probabilidade de $r_{2}$, por exemplo, é tal que $p(-5 \%)=P\left(R_{i}=-5 \%\right)=20 \%$.

A função massa de probabilidade de uma v.a. discreta deve atender certas premissas básicas (ROSS, 2010). Primeiramente, o valor de $p\left(r_{i}\right)$ é sempre positivo para todos os valores discretos de $R_{i}$ e se encontra no intervalo $[0,1]$. Isto é, se $R_{i}$ assume um dos valores $r_{1}, r_{2}, \ldots, r_{n}$, então:

$$
\begin{aligned}
& 0 \leq p\left(r_{i}\right) \leq 1, i=1,2, . ., n \\
& p\left(r_{i}\right)=0, i \neq 1,2, . ., n
\end{aligned}
$$

Além disso, a função massa de probabilidade distribui o total de 1 unidade de probabilidade por todo o conjunto de valores que a v.a. discreta pode assumir. Significa que a soma dos valores de $p\left(r_{i}\right)$ para todo o conjunto de valores de $R_{i}$ deve ser igual a 1 :

$$
p\left(r_{1}\right)+p\left(r_{2}\right)+\ldots p\left(r_{n}\right)=\sum_{i=1}^{t} p\left(r_{i}\right)=1(4)
$$

A distribuição probabilística dos retornos da ação do nosso exemplo pode ser ilustrada no gráfico a seguir. No eixo horizontal temos os valores de $R_{i}$, dados por $r_{1}$ a $r_{5}$, enquanto que no eixo vertical temos os valores da função massa de probabilidade para cada ocorrência. 


\section{Gráfico 1 - Distribuição probabilística discreta dos retornos}

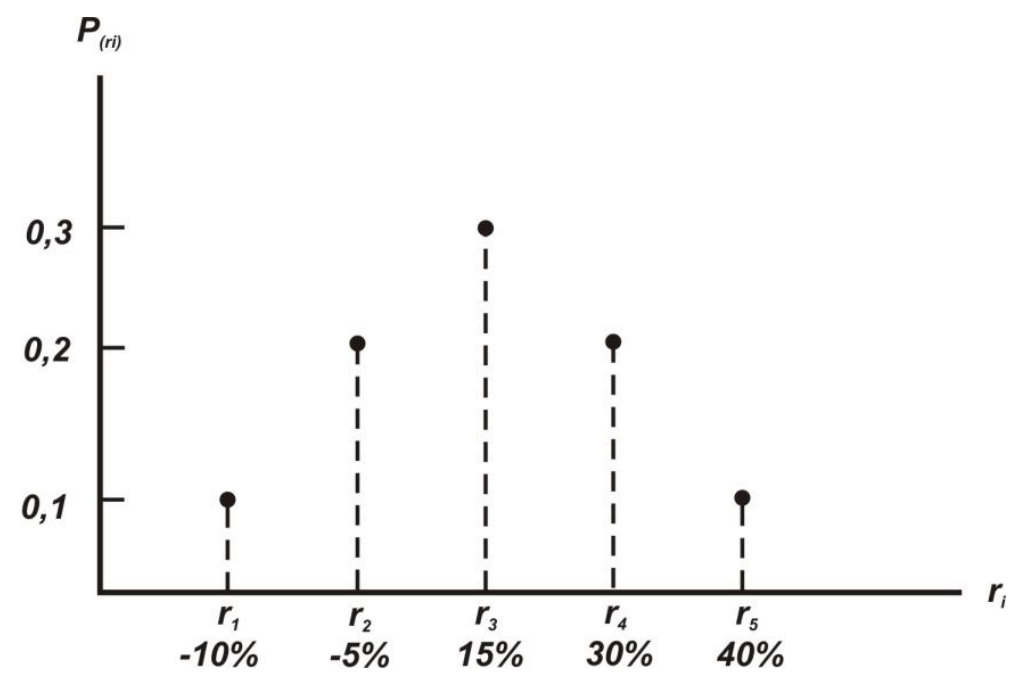

Fonte: Elaborada pelo autor.

Ao se trabalhar empiricamente com a série de retornos de um ativo financeiro, é necessário, portanto, definir-se previamente o espectro probabilístico que guiará a análise: se os retornos serão avaliados como discretos ou contínuos. Geralmente, trabalha-se com retornos na sua forma discreta, na medida em que esta abordagem permite uma maior simplificação dos cálculos. Entretanto, a abordagem contínua é mais realista, principalmente se estamos lidando com uma grande amostra de observações, porquanto os retornos contínuos permitem a construção de uma distribuição de probabilidade economicamente mais significante (JORION, 1998).

\subsection{Os Retornos Obtidos}

Para efeito de classificação das diferentes espécies de retorno financeiro, costuma-se dividir os ativos negociados no mercado de capitais em instrumentos de renda fixa e de renda variável. Os títulos de renda fixa oferecem uma taxa prometida de retorno, associada a uma determinada taxa de juros - existe, portanto, um parâmetro que define sua rentabilidade. Já os títulos de renda variável, tais como as ações, não apresentam uma taxa prometida de retorno, ou seja, não há a promessa de pagamento de dinheiro no futuro (BODIE; MERTON, 2002).

De fato, quando o investidor aplica o seu capital em títulos acionários, o retorno obtido pela aplicação do capital pode ser decomposto em dois componentes. O primeiro consiste no pagamento de dividendos aos acionistas. Os dividendos dependerão dos critérios definidos pela empresa, a depender do lucro arrematado, e por isso não há garantia de recebimento. Portanto, como não existe uma taxa prometida de retorno, os dividendos não podem ser considerados como juros. Já o segundo componente diz respeito aos ganhos ou perdas no preço de mercado das ações dentro de um determinado período 
(dias, meses, anos, etc.), sendo esse retorno chamado de ganho ou perda de capital $^{5}$ (ROSS; WESTERFIELD, 1997).

Assim, definindo-se um determinado horizonte de mensuração, como um mês, por exemplo, os retornos absolutos obtidos pela realização de investimentos em ativos financeiros são dados pela diferença entre o valor do título ao final do mês corrente, denotado por $P_{t}$, e o valor do título ao final do mês anterior, denotado por $P_{t-1}$. Já o retorno percentual ou taxa de retorno discreta de um determinado título $i$ é definido como o ganho de capital ocorrido durante esse período, considerando-se discretos os valores da variável aleatória $R_{i}$ (COSTA; ASSUNÇÃO, 2005):

$$
R_{i}=\frac{P_{t}-P_{t-1}}{P_{t}}
$$

Para investimentos em ações, as quais podem oferecer dividendos, denotados por $D_{i}$, e desconsiderando os efeitos inflacionários, tem-se que a taxa de retorno é dada por (BODIE; MERTON, 2002):

$$
R_{i}=\frac{P_{t}-P_{t-1}+D_{t}}{P_{t}}
$$

É possível também representar a taxa de retorno através de seus dois componentes, o dividendo e a variação no preço de mercado da ação:

$$
R_{i}=\frac{D_{t}}{P_{t}}+\frac{P_{t}-P_{t-1}}{P_{t}}
$$

As definições (6) e (7) implicam, necessariamente, que qualquer rendimento advindo de dividendos será reinvestido no final do mês, na compra de mais ações.

Se, por outro lado, estivermos tratando com retornos de horizonte longo, é mais conveniente considerar os valores obtidos de $R_{i}$ como contínuos. Assim, a taxa de retorno continuamente composta de $R_{i}$, também chamada de log retorno é definido em termos do logaritmo da razão do preço (MORETTIN; TOLOI, 2006):

\footnotetext{
${ }^{5}$ As perdas de capital são também chamadas de ganhos negativos de capital.
} 


$$
R_{i}=\ln \left(\frac{P_{t}}{P_{t-1}}\right)=\ln P_{t}-\ln P_{t-1}
$$

Com o adendo de dividendos, a taxa de retorno contínua é dada por:

$$
R_{i}=\ln \left[\frac{\left(P_{t}+D_{t}\right)}{P_{t-1}}\right]=\ln \left(P_{t}+D_{t}\right)-\ln P_{t-1}
$$

Uma das vantagens de se utilizar retornos contínuos é o fato de permitirem, com facilidade, extensões para múltiplos períodos. Considere, por exemplo, o retorno sobre um período de três meses. O retorno logaritmo pode ser decomposto como:

$$
R_{i, 3}=\ln \left(\frac{P_{t}}{P_{t-3}}\right)=\ln \left(\frac{P_{t}}{P_{t-1}}\right)+\ln \left(\frac{P_{t-1}}{P_{t-2}}\right)+\ln \left(\frac{P_{t-2}}{P_{t-3}}\right)=R_{t-2}+R_{t-1}+R_{t}
$$

O que é particularmente conveniente, já que o retorno contínuo de três meses é simplesmente a soma de três retornos mensais.

Por fim, pode o investidor desejar conhecer o seu retorno acumulado, aquele que ganharia caso mantivesse seu investimento por vários períodos seguidos. Considerando o rendimento obtido a cada mês de aplicação, o retorno acumulado ao final de $t$ meses é tal que:

$$
R_{a c m}=\left[\prod_{i=1}^{t}\left(1+R_{i}\right)\right]-1
$$

A depender do tratamento despendido aos dados, existem como elencados diversas formas de se calcular o retorno realizado de um título financeiro, seja ele de risco ou não. O cálculo dos retornos obtidos em períodos passados, como veremos, é de grande importância para a construção das expectativas quanto ao futuro desempenho do investimento empreendido.

\subsection{O Retorno Esperado de Ativos Financeiros}

Através do conjunto de preços e dividendos passados de um ativo financeiro, é possível construir a série histórica de retornos realizados, fixandose para tanto uma janela temporal de análise. Entretanto, para o investidor, o importante é a sua rentabilidade futura, aquela que será obtida após o 
momento em que se decide investir. Apesar de não ser possível prever o retorno futuro com exatidão, é necessário que o investidor detenha uma estimativa dos próximos retornos, a fim de auxiliá-lo na tomada de decisão quanto à alocação de seu capital. Nesse sentido, a informação acerca do comportamento anterior de um ativo, representado na forma do cálculo dos retornos ocorridos no passado, serve de base para o investidor formar suas expectativas quanto ao futuro desempenho do seu investimento.

Em linhas gerais, o retorno que o investidor espera obter no futuro ou no período seguinte ao seu investimento é definido como retorno esperado (JORION, 1998). $\mathrm{Na}$ análise, o retorno esperado de um ativo financeiro é obtido através da utilização de uma das principais características de uma variável aleatória: a esperança matemática, também chamada de valor esperado, primeiro momento ou valor médio da variável aleatória. A esperança matemática é o valor de tendência central da distribuição de probabilidade de uma variável aleatória, ou seja, é o valor médio que uma v.a. assume em um número infinito de repetições de um experimento. Se observarmos um experimento um grande número de vezes, a v.a. tenderá a assumir determinado valor, sendo este o seu valor esperado ou valor médio.

Considere que o retorno $R_{i}$ de uma ação é uma v.a. discreta que pode tomar os valores $r_{1}, r_{2}, \ldots, r_{n}$, com probabilidades $p\left(r_{1}\right), p\left(r_{2}\right), p\left(r_{n}\right)$, obtidas pela sua função massa de probabilidade $p\left(r_{i}\right)$. A sua esperança matemática, ou valor esperado, denotado por $E\left(R_{i}\right)$, é dado por (ROSS, 2010):

$$
E\left(R_{i}\right)=r_{1} p\left(r_{1}\right)+r_{2} p\left(r_{2}\right)+\ldots+r_{n} p\left(r_{n}\right)=\sum_{i=1}^{t} r_{i} p\left(r_{i}\right)
$$

Onde $E\left(R_{i}\right)$, como retorno médio, é freqüentemente indicado por $\mu$ :

$$
E\left(R_{i}\right)=\mu
$$

A equação acima nos mostra que o retorno esperado é uma média ponderada dos valores discretos que $R_{i}$ pode assumir, tendo como ponderações as probabilidades associadas a cada ocorrência. Dada uma série de retornos efetivos passados, variando do período 1 a $t$, o retorno que 0 investidor espera obter no próximo período, $t+1$, é igual ao somatório do produto desses retornos pelas suas respectivas probabilidades.

A esperança matemática possui algumas propriedades úteis, que valem tanto se o retorno de um ativo for considerado uma v.a. discreta ou contínua. Temos que, se $c$ é uma constante que multiplica $R_{i}$, o valor esperado é igual a $c$ vezes o retorno esperado:

$$
E\left(c R_{i}\right)=c E\left(R_{i}\right)
$$


Ademais, o valor esperado da soma ou da diferença de dois retornos $R_{i}$ e $R_{j}$ é igual a soma ou a diferença entre os próprios retornos esperados:

$$
E\left(R_{i} \pm R_{j}\right)=E\left(R_{i}\right) \pm E\left(R_{j}\right)
$$

Em todo caso, o retorno esperado de um ativo costuma ser estimado, na prática, pressupondo-se que em toda a população de observações passadas os retornos apresentam a mesma probabilidade de ocorrência. Ou seja, pressupõe-se que os retornos são identicamente distribuídos e equiprováveis. Este método é aplicado visto que, geralmente, não se tem acesso à verdadeira distribuição probabilística dos retornos. Nesse caso, se $t$ é a quantidade de retornos observados, o retorno esperado ou primeiro momento $\mu=E\left(R_{i}\right)$ pode ser estimado pela média amostral dos retornos passados:

$$
\hat{\mu}=\bar{R}_{i}=\frac{\sum_{i=1}^{t} r_{i}}{t}
$$

Onde se assume que $\hat{\mu}$ se aproxima de $\mu$, o verdadeiro valor esperado da variável aleatória $R_{i}$. Em suma, estamos considerando que o investidor tem como estimativa do retorno futuro de sua ação a média dos retornos que o título tenha obtido no passado.

Entretanto, devemos ter em mente que, como se trata de uma expectativa, o retorno que efetivamente ocorrerá poderá ser superior ou inferior ao retorno esperado. Cabe ao investidor, portanto, determinar o método no qual suas expectativas estarão baseadas, a fim de captar ao máximo o movimento futuro do ativo. Geralmente, assume-se que o retorno esperado de um título seja igual ao retorno médio que este tenha apresentado passado, como foi aqui desenvolvido. Não obstante, outros métodos podem ser considerados, como a aplicação de modelos mais robustos de previsão ou mesmo se o investidor possui determinada informação privilegiada que possa auxiliá-lo na formação de suas expectativas (ROSS; WESTERFIELD, 1997).

\subsection{Medidas de Risco}

O conceito de risco financeiro atinge as mais variadas esferas da sociedade, sejam empresas, indivíduos ou governo. De fato, toda empresa tem seu risco financeiro e os seus negócios estão intrinsecamente ligados à administração do risco. Da mesma forma, os investidores individuais incorrem em risco quando da formulação de suas carteiras, independente da soma de capital que despendam na sua composição. A busca de rendimentos oriundos 
de ativos financeiros traz, inevitavelmente, um determinado risco associado. Assim, os agentes que estejam atuando no mercado de capitais, supondo-os racionais e avessos à volatilidade de seus investimentos, devem buscar maximizar o seu retorno dentro de um nível de risco aceitável (JORION, 1998).

$\mathrm{Na}$ literatura, apesar do risco ser tratado sob diferentes abordagens todas convergem para o entendimento de que o mesmo é algo desfavorável, prejudicial e contrário ao interesse esperado pelo agente. JORION (1998, p.3) define o risco como a "volatilidade de resultados inesperados, normalmente relacionada ao valor de ativos ou passivos de interesse". Já MERTON e BODIE (2002, p. 258) tratam o risco sob o ponto de vista da incerteza. Para estes autores, a incerteza "existe sempre que não se sabe ao certo o que vai ocorrer no futuro". Sendo assim, "o risco é a incerteza que importa, porque afeta o bem-estar das pessoas", já que "toda situação de risco é incerta, mas pode haver incerteza sem risco" (idem). ROSS, (2010, p. 194-195) reitera que não há uma definição de risco universalmente aceita, mas propõe que uma das maneiras de se pensar o risco em ativos financeiros é analisar o grau de dispersão da distribuição de frequência dos retornos: "a dispersão de uma distribuição é uma medida de quanto um dado retorno pode se afastar do retorno médio. Se a distribuição apresentar uma dispersão muito grande, os retornos que poderão ocorrer serão muito incertos". Em outras palavras, podese inferir que a incerteza e o risco estão atrelados e, portanto, retornos incertos podem ser entendidos como retornos arriscados.

O desvio-padrão e a variância são as medidas de dispersão utilizadas para se auferir estatisticamente o risco. Supondo um determinado ativo financeiro com retorno $R_{i}$, a sua variância, denotada por $\operatorname{Var}\left(R_{i}\right)$ ou $\sigma^{2}$, é dada pelo segundo momento da distribuição de probabilidade das observações. Ou seja, é a diferença quadrática média entre os valores assumidos por $R_{i}$ e o seu valor esperado:

$$
\operatorname{Var}\left(R_{i}\right)=\sigma^{2}=E\left[R_{i}-E\left(R_{i}\right)\right]^{2}=E\left[R_{i}^{2}\right]-\left[E\left(R_{i}\right)\right]^{2}
$$

Assim, temos que a variância do retorno é a média ponderada dos quadrados das diferenças (ou distâncias) entre os valores que $R_{i}$ pode tomar e o seu valor esperado ou médio (o centro da função de distribuição de probabilidade). Quanto maior a variância de um título, maior será a distância quadrática média entre os valores do retorno e sua média, ou seja, mais dispersos serão os rendimentos - o que representa um maior risco incorrido.

Uma propriedade muito útil das variâncias é que, se $c$ é uma constante que multiplica o retorno, a variância será igual ao quadrado da constante vezes a variância do retorno:

$$
\operatorname{Var}\left(c R_{i}\right)=c^{2} \operatorname{Var}\left(R_{i}\right)
$$


Para o cálculo efetivo da variância, devemos antes estabelecer se 0 retorno do ativo se comporta de forma contínua ou discreta. Considerando o retorno como uma v.a. discreta com valores $r_{i}$, com função massa de probabilidade $p\left(r_{i}\right)$, a variância é dada por:

$$
\sigma^{2}=\sum_{i=1}^{t}\left[r_{i}-E\left(R_{i}\right)\right]^{2} p(r i)
$$

Se o cálculo da variância for realizado com base na população de retornos passados, onde se admite que todos os valores tivessem a mesma probabilidade de ocorrência, a variância populacional da distribuição de retornos pode ser estimada da seguinte forma:

$$
\sigma^{2}=\frac{\sum_{i=1}^{t}\left(r_{i}-\bar{R}_{i}\right)^{2}}{t}
$$

Quando o cálculo for realizado considerando-se apenas uma amostra da população, um estimador não tendencioso da variância amostral poderá ser calculado do seguinte modo:

$$
\sigma^{2}=\frac{\sum_{i=1}^{t}\left(r_{i}-\bar{R}_{i}\right)^{2}}{t-1}
$$

A equação (21) pode ser expandida da seguinte forma:

$$
\sigma^{2}=\frac{1}{t-1} \sum_{i=1}^{t} r_{i}^{2}-\frac{t}{t-1} \bar{R}_{i}^{2}
$$

O que nos mostra que a variância é composta por dois termos: o primeiro é a média dos retornos quadrados e o segundo é o quadrado da média.

No entanto, o fato de a variância ser medida em quadrados torna esta medida um número grande e de difícil manejo, pois seu valor sai dos limites dos valores observados em um conjunto de dados. Além disso, os retornos obtidos ao se investir em um título não são calculados em termos quadráticos, como se demonstra nas equações (17) a (22). Necessita-se, pois, de uma medida representativa de risco que esteja na mesma escala dos retornos 
financeiros. Isto pode ser solucionado através da utilização do conceito de desvio-padrão. O desvio-padrão é nada mais do que a raiz-quadrada da variância, geralmente representado por DP $\left(R_{i}\right)$ ou $\sigma$ :

$$
D P\left(R_{i}\right)=\sigma=\sqrt{\frac{\sum_{i=1}^{t}\left(r_{i}-\bar{R}_{i}\right)^{2}}{t-1}}
$$

Ao se retirar a raiz quadrada da variância, o valor resultante adentra novamente nos limites dos retornos observados da amostra. Nesse sentido, o desvio-padrão representa o erro médio obtido ao se substituir cada valor do conjunto de dados pela média amostral (no caso dos retornos, o erro médio gerado ao se substituir cada valor $r_{i}$ pelo retorno médio $\bar{R}_{i}$ ).

Uma propriedade do desvio-padrão que deriva da variância é que, considerando uma constante $c$ que multiplica o retorno, o desvio-padrão é igual as constantes vezes o desvio-padrão do retorno:

$$
D P\left(c R_{i}\right)=c D P\left(R_{i}\right) \mathrm{n}(24)
$$

Isto resulta da equação (2.24) e do fato de que a raiz quadrada do produto de dois números é o produto de cada um dos números.

Observa-se, portanto, que pelo fato do desvio-padrão ser expresso na mesma unidade escalar da variável analisada, esta medida pode ser utilizada para melhor descrever a quantidade de dispersão na distribuição dos retornos, representando assim o risco da ação ${ }^{6}$.

Após discutir, neste capítulo, as definições de retorno e risco de títulos individuais, é propósito mostrar como estes conceitos são utilizados no modelo de CAPM.

\section{MODELO DE PRECIFICAÇÃO DE ATIVOS FINANCEIROS - CAPM}

Mensurar o risco não é tarefa simples. A matemática para o cálculo do risco exige um conhecimento da teoria da probabilidade e de como os riscos e retornos dos ativos se comportam dentro de um modelo significativo. Um dos mais bem sucedidos modelos de mensuração do risco é denominado CAPM (GROPPELLI; NIKBAKHT, 2009).

O modelo de precificação de ativos financeiros (CAPM) relaciona os riscos sistemáticos ou não diversificáveis aos retornos esperados de um

${ }^{6} \mathrm{O}$ desvio-padrão é costumeiramente chamado de volatilidade, principalmente em se tratando de retornos contínuos (JORION, 1998). 
projeto. Apesar de ser mais indicado para a análise de ativos financeiros, também pode ser utilizado na avaliação de risco e retorno de investimentos e ativos empresariais (GROPPELLI; NIKBAKHT, 2009). Como também na determinação do custo de capital próprio (MARTELANC; PEREIRA; PASIN 2005).

O custo de capital é a taxa mínima de retorno necessária para atrair investidores. Em outras palavras, é a taxa que o investidor pode obter em outras modalidades semelhantes de investimento. Outra maneira de destacar o custo de capital é como sendo a taxa de retorno que torna indiferente, para o investidor a aprovação ou não de um projeto (MARTELANC; PEREIRA; PASIN 2005).

De acordo com as definições de custo de capital, podem-se observar as inúmeras aplicabilidades da análise do custo de capital: Avaliação do desempenho empresarial; avaliação de investimentos; avaliação de decisões de financiamento; nas operações da empresa; e principalmente na escolha de uma carteira de ativos (MARTELANC; PEREIRA; PASIN, 2005)

O pressuposto básico do CAPM é a existência de um relacionamento próximo entre os retornos dos ativos individuais e os retornos do mercado. Os retornos de uma carteira de ativos consistem nos ganhos de capital e das receitas com dividendos. Também é destacado que o mercado de ativos é altamente eficiente e de assimilação rápida de todas as informações disponíveis. (GROPPELLI; NIKBAKHT, 2009)

Assim, devido a esse relacionamento próximo, a instabilidade do mercado nos apresenta um coeficiente comum para a determinação do grau de risco de um ativo individual. Esse grau de risco é definido pelo nível de sensibilidade dos retornos de um ativo em relação ao mercado. Dessa forma, relaciona um índice comum medido pela sensibilidade do ativo individual em confronto com um índice comum, caracterizado pelo mercado. Quando o retorno do ativo sobe ou desce numa proporção maior que o do mercado, indica que o ativo possui risco maior que o mercado. Se o retorno do ativo sobe ou desce numa proporção menor que o do mercado, diz-se que o ativo possui risco menor que o do mercado. Pode-se, também, classificar os riscos de vários ativos apenas relacionando-os ao índice comum do mercado (GROPPELLI; NIKBAKHT, 2009). mercado?

Mas como determinar a sensibilidade de um ativo em relação ao

A sensibilidade de um ativo em relação ao mercado pode ser determinada, de forma simplificada, pela comparação entre os desvios-padrão do ativo e do mercado, tal que (GROPELLI; NIKBAKHT, 2009):

$$
\text { Sensibilidade }=\frac{\text { volatilidadedosretornosdoativoj }\left(\sigma_{j}\right)}{\text { volatilidadedosretornosdomercadom }\left(\sigma_{m}\right)}(25)
$$


O modelo CAPM aborda, de forma mais completa, a sensibilidade através da análise do coeficiente beta $(\beta)$, porém o conceito é bastante semelhante (GROPPELLI; NIKBAKHT, 2009).

O coeficiente beta $(\beta)$ pode ser considerado o coeficiente do risco específico de um ativo em relação ao índice representativo do mercado. No caso de uma firma com expressiva participação na bolsa de valores, o beta de sua ação pode ser determinado pela regressão de seus retornos periódicos em relação ao índice de mercado selecionado em períodos anteriores (MARTELANC; PEREIRA; PASIN, 2005).

No modelo CAPM, o coeficiente beta $(\beta)$ é dado pela variação entre os retornos dos ativos, caracterizados por $\left(R_{j}\right)$ e os retornos médios do mercado $\left(R_{m}\right)$. Esse valor de beta $(\beta)$ mede necessariamente a sensibilidade ou risco de um ativo em relação ao mercado. Estatisticamente pode-se escrever essa relação na forma de uma linha característica, como descrita abaixo (GROPPELLI; NIKBAKHT, 2009).

$$
R_{j}=a+\beta R_{m}+e
$$

Onde, $\beta$ é o coeficiente de sensibilidade, $R_{m}$ é o retorno médio do mercado, $R_{j}$ é o retorno do ativo j, $a$ é um constante e $e$ é o erro.

Outra maneira de definirmos o valor de beta $(\beta)$ é como a medida de volatilidade dos retornos de um título com relação aos retornos do mercado como um todo, podendo ser calculado pela fórmula (MARTELANC; PEREIRA; PASIN, 2005):

$$
\beta_{j}=\frac{\operatorname{Cov}\left(R_{j}, R_{m}\right)}{\sigma^{2}\left(R_{m}\right)} \text { ou } \rho\left(R_{j}, R_{m}\right) \cdot \frac{\sigma R_{j}}{\sigma R_{m}}(28)
$$

Onde, $\beta_{j}$ é o beta do ativo j, $\operatorname{Cov}\left(R_{j}, R_{m}\right)$ é a covariância entre os retornos do ativo j e a carteira do mercado, $\sigma^{2}\left(R_{m}\right)$ é a variância dos retornos da carteira de mercado, $\rho\left(R_{j}, R_{m}\right)$ é o coeficiente de correlação entre os retornos dos ativos j da carteira de mercado $\mathrm{m}, \sigma R_{j}$ é o desvio padrão dos retornos do ativo j e $\sigma R_{m}$ é o desvio padrão dos retornos do mercado.

O resultado do beta é o mesmo do derivado da linha característica. Deve-se considerar o fator coeficiente de relação de forma que quanto menor o coeficiente, menor será o beta, logo menor será o risco não diversificável (GROPPELLI; NIKBAKHT, 2009).

A fórmula do beta proporciona dois aspectos importantes sobre 0 mesmo. O risco do ativo, que é tão grande quanto for o quociente entre o seu desvio padrão e o do mercado e que esse risco é proporcional ao coeficiente 
de correlação entre o ativo e o mercado. (MARTELANC; PEREIRA; PASIN 2005).

Assim, a interpretação para os possíveis resultado do beta é, conforme Martelanc et. al. (2005):

\begin{tabular}{|c|c|}
\hline \multicolumn{2}{|c|}{ sadro 1 - Interpretações dos $\beta$} \\
\hline Beta & Interpretação \\
\hline$\beta=1,0$ & $\begin{array}{l}\text { O ativo possui o mesmo risco que o } \\
\text { mercado. Isto é, se o mercado subir } \\
5 \% \text {, o ativo tenderá a subir } 5 \% \text {. O } \\
\text { efeito negativo se dará da mesma } \\
\text { maneira. }\end{array}$ \\
\hline$\beta>1,0$ & $\begin{array}{l}\text { O ativo possui risco maior que o risco } \\
\text { do mercado. Isto é, se o mercado } \\
\text { subir } 5 \% \text {, o ativo tenderá a subir mais } \\
\text { que } 5 \% \text {. O efeito negativo se dará da } \\
\text { mesma maneira. }\end{array}$ \\
\hline$\beta<1,0$ & $\begin{array}{l}\text { O ativo possui risco menor que o riscc } \\
\text { do mercado. Isto é, se o mercado } \\
\text { subir } 5 \%, \text { o ativo tenderá a subir } \\
\text { menos que } 5 \% \text {. O efeito negativo se } \\
\text { dará de forma análoga. }\end{array}$ \\
\hline
\end{tabular}

Fonte: Elaborado pelo autor.

O beta também é utilizado para a identificação da recompensa do ativo dado o seu risco. A relação entre a variação do retorno esperado de uma carteira de ativos e a variação correspondente dos possíveis betas de uma carteira é denominada quociente entre recompensa e risco, isto é, quociente recompensa/risco, também denominado de índice de Treynor em homenagem a um dos seus criadores. Este índice mede quanto de recompensa o ativo dará para cada nível de risco sistemático (ROSS; WESTERFIELD, 1997).

$$
\text { Quociente } \frac{\text { Recompensa }}{\text { Risco }}=\frac{R_{j}-R_{f}}{\beta_{j}}
$$

O quociente entre recompensa e risco deve ser sempre o mesmo para todos os ativos no mercado. Se o quociente entre recompensa e risco de um ativo for maior que o outro, todos os investidores irão demandar somente aquele ativo de maior recompensa por risco. Assim, os preços dos ativos de menor recompensa por risco cairiam e dado que as taxas de retorno e os preços variam de maneiras opostas, a recompensa por risco iria aumentar. Essas sequências de compras e vendas de ativos fariam com que, para todo ativo $i$ e $j$ (ROSS; WESTERFIELD, 1997): 


$$
\frac{R_{i}-R_{f}}{\beta_{i}}=\frac{R_{j}-R_{f}}{\beta_{j}}(30)
$$

O CAPM apresenta uma medida alternativa do risco para cada desviopadrão do ativo. É evidente que o modelo CAPM facilita a comparação das varias escalas de risco dos ativos individuais. Mas, como empregar o beta na obtenção da taxa de retorno efetiva? Para isso, deverá ser usado o princípio da linha de mercado de títulos (SML) (GROPPELLI; NIKBAKHT, 2009).

A linha determinada quando se representa graficamente a relação entre risco não diversificável e o retorno esperado dos mercados financeiros é denominada de linha de mercado de títulos (SML). Uma das maneiras frequentes de se escrever a SML é considerando uma carteira que engloba todos os ativos do mercado, está carteira será denominada de carteira de mercado. (ROSS; WESTERFIELD, 1997).

Sendo que todos os ativos do mercado devem estar localizados na SML, o mesmo deve ocorrer com a carteira de mercado. Para que seja determinada em que ponto da SML a carteira de mercado encontra-se, é preciso saber qual o valor do coeficiente beta $\left(\beta_{m}\right)$ da carteira de mercado. Como essa carteira representa todos os ativos do mercado, o beta deve ser igual à média, logo, $\beta=1,0$. Assim, a inclinação da SML será dada por (ROSS; WESTERFIELD, 1997):

$$
\text { Inclinação da } S M L=\frac{R_{m}-R_{f}}{\beta_{m}}=\frac{R_{m}-R_{f}}{1}=R_{m}-R_{f}
$$

A inclinação da SML, $\left(R_{m}-R_{f}\right)$, é considerada o prêmio por risco de uma carteira de mercado. O prêmio pelo risco de uma carteira de mercado é a diferença entre a taxa de retorno que se espera do mercado e a taxa de retorno dos ativos livre de riscos. Visto que o retorno do mercado é incerto e necessário que haja um prêmio de tal forma que o investidor prefira reter um portfólio do mercado em vez de ativos sem risco, cujo retorno é praticamente conhecido (MARTELANC; PEREIRA; PASIN, 2005).

Como, $R_{j}$ e $\beta_{j}$ são, respectivamente, o retorno esperado e o beta de qualquer ativo do mercado e consequentemente estão situados na SML. Dessa maneira, sabe-se que o seu quociente entre recompensa e risco deve ser idêntico ao do mercado, logo (ROSS; WESTERFIELD, 1997):

$$
\frac{R_{j}-R_{f}}{\beta_{j}}=R_{m}-R_{f}
$$

Assim, a taxa de retorno de um ativo será encontrada pela soma da taxa de retorno de um ativo sem risco e um prêmio pelo risco. Sendo, esse prêmio pelo risco de um ativo, definido pelo retorno médio do mercado subtraído pela taxa de retorno do ativo sem risco $\left(R_{m}-R_{f}\right)$ multiplicado pelo grau de 
sensibilidade do ativo, ou risco não diversificável, chamado beta $(\beta)$. Assim, dado a taxa de retorno do mercado, obtêm-se (GROPPELLI; NIKBAKHT, 2009):

$$
R_{j}=R_{f}+\beta\left(R_{m}-R_{f}\right)
$$

Essa é a versão clássica do CAPM onde $R_{j}$ é o retorno esperado do ativo; $R_{f}$ é o retorno do ativo sem risco; $R_{m}$ é o retorno esperado da carteira do mercado; e $\beta$ é a sensibilidade do ativo em relação ao mercado (MARTELANC; PEREIRA; PASIN, 2005).

Nesse resultado, o CAPM mostra que o retorno esperado de um ativo depende necessariamente: do valor puro do capital no tempo, quantificado pela taxa livre de risco $\left(R_{f}\right)$; do prêmio pelo risco sistemático assumido $\left(R_{m}-R_{f}\right)$, determinado pelo prêmio do risco da carteira de mercado e do grau de risco sistemático $\left(\beta_{j}\right)$, determinado pela quantidade de risco sistemático presente em um ativo (ROSS; WESTERFIELD, 1997).

As características principais do método CAPM são: a eliminação do risco não sistemático por meio da diversificação por parte do investidor e a concentração de investimentos em ativos sem risco, na carteira do mercado ou em uma combinação de ambos (MARTELANC; PEREIRA; PASIN, 2005). O CAPM é utilizado tanto para carteira de ativos quanto para ativos individuais (ROSS; WESTERFIELD, 1997).

O CAPM inicia-se com a taxa livre de risco e, então, acrescenta um prêmio pelo risco, conforme visto, e um ajuste de proporcionalidade chamado beta. A SML define a taxa de retorno de um ativo para um beta qualquer. Sempre que o retorno de um ativo for menor que sua taxa, isto quer dizer, que o ativo tem menor valor que o esperado, logo, este ativo está superavaliado. Quando a taxa de retorno é maior que a esperada, quer dizer, então, que os ativos estão subavaliados. Essa relação apresenta a forma da linha de mercado de títulos (SML), a qual é a representação gráfica do modelo CAPM. O método da SML, por apresentar a taxa de desconto do ativo, ajuda a determinação do valor presente e a rentabilidade do ativo (GROPPELLI; NIKBAKHT, 2009).

As abordagens do CAPM e da SML fornecem alguns problemas. A existência de outros fatores, de maior importância que o mercado, na influência dos retornos esperados de um ativo torna o beta uma medida de risco não confiável. Os índices de mercado utilizados - como o Standard \&Poor's, índice Down Jones - no modelo CAPM são considerado fracos pelos acadêmicos, pois são apenas substitutos e, assim, não representam um verdadeiro índice de mercado. Outro problema está nos cálculos de valores do CAPM, acreditase que os dados utilizados são históricos, enquanto que o modelo baseia-se em valores esperados. De tal forma que, os betas históricos não podem servir de base para o estabelecimento da taxa esperado de retorno do ativo (GROPPELLI; NIKBAKHT, 2009). 
Outros estudos, como o de Fama e French indicam que o índice de mercado apresenta uma correlação com os retornos esperados pequenos, logo, não podendo servir como índice comum para determinação do coeficiente de risco não sistemático, beta e da SML. Isto indica que, para alguns autores, o beta e consequentemente o CAPM não são validos. Porém, em resposta às críticas apresentadas, se reitera aos conceitos de CAPM como válidos, necessitando de uma pesquisa de índices comuns mais apropriadas na obtenção de betas mais confiáveis (GROPPELLI; NIKBAKHT, 2009).

As ideias que embasam a abordagem do CAPM apresentam apenas aproximações imperfeitas. Porém servem, ainda, como ferramenta alternativa para a determinação do prêmio dado pelo risco e retorno dos ativos. Necessitando apenas de descobrir uma relação de fatores que possam ser utilizadas com medida representativa comum (GROPPELLI; NIKBAKHT, 2009).

\section{CAPM: UM ESTUDO DE CASO}

\subsection{Conjuntura do Mercado Frigorífico}

A bovinocultura é um dos principais destaques do (USA-SE DE AGRONEGÓCIO OU DO AGRONEGÓCIO?) agronegócio brasileiro no cenário internacional. O Brasil é dono do segundo maior rebanho efetivo do mundo, com cerca de 200 milhões de cabeças. Ademais, desde 2004, assumiu a liderança nas exportações, com um quinto da carne comercializada internacionalmente e vendas em mais de 180 países.

O rebanho bovino brasileiro proporciona o desenvolvimento de dois segmentos lucrativos: o primeiro as cadeias produtivas de carne e o segundo as de leite. $O$ valor bruto da produção desses dois segmentos estimado em $R \$$ 67 bilhões e aliado à presença da atividade em todos os estados brasileiros, evidenciando a importância econômica e social da bovinocultura em nosso país.

O rebanho brasileiro está estimado em torno de 1,15 milhões de bubalinos, sendo a região Norte, com 720 mil animais, a maior produtora do País, com destaque para o Pará, que responde por 39\% do rebanho nacional. Em seguida aparecem o Nordeste e o Sudeste, com 135 e 104 mil cabeças, respectivamente.

Mato Grosso do Sul ocupa a quarta posição na lista nacional de estados com maiores rebanhos bovinos, com 21, 498 milhões de animais, o que representa $10,2 \%$ do total brasileiro. Os estados que ocupam as três primeiras colocações são Mato Grosso, com 27, 740 milhões de animais; Minas Gerais, com 23,965 milhões e Goiás, com 22,045 milhões de bovinos.

A produção brasileira de carne bovina cresceu $62 \%$ nos últimos 20 anos, chegando a 9,3 milhões de toneladas em 2012, ocupando o segundo lugar no ranking dos países produtores; sendo superado pelos EUA com 12,04 milhões de toneladas. A produção brasileira supera os $15 \%$ do total mundial, conforme 
informações do Departamento de Agricultura dos Estados Unidos (USDA) e a Organização das Nações Unidas para a Agricultura e a Alimentação (FAO).

As instituições supracitadas apontam três fatores principais como justificativa para o aumento da produção nacional: [1] o crescente volume de exportações; [2] o aumento da demanda interna, impulsionada pelo crescimento esperado da economia; [3] e o maior poder aquisitivo da população, que tende a aumentar o consumo de proteína animal.

O Estado de São Paulo responde por $10,7 \%$ dos abates do País, ocupando o segundo lugar no ranking nacional (IBGE - 2012). Essa participação é superior a do rebanho bovino do Estado no total nacional (5\%), indicando que São Paulo importa gado de outros Estados para abate em seu parque industrial (IBGE - 2012).

As principais regiões produtoras do Estado são Presidente Prudente, São José do Rio Preto, Araçatuba e Bauru.

O investimento na pecuária no Estado de São Paulo é um crescente constante por causa:

[1] da qualidade genética dos rebanhos;

[2] dos programas de manejo sanitário;

[3] das campanhas de vacinação contra as principais enfermidades.

[4] do sistema de produção livre de hormônios, que preza pelo bem-estar animal, fazendo com que a carne seja uma das mais saudáveis do mundo.

[5] do principal centro de consumo de carne do Brasil.

O segmento do mercado de carne enquanto atrelado ao setor frigorífico encontra-se diretamente vinculado ao crescimento econômico mundial, refletindo diretamente o panorama de consumo familiar mundial. Segundo relatório setorial, no ano de 2010, o rebanho bovino mundial apresentou queda de 1,7\% (de 1, 010 bilhão em 2009 para 992 milhões em 2010) e queda na taxa de desfrute de $23,4 \%$ em 2009 para $23 \%$ em 2010. Consequentemente os preços internacionais visualizaram uma elevação no ano. Ao contrário a tendência mundial, o rebanho bovino brasileiro aumentou 3,7\%, porém, com uma queda de desfrute de $21,3 \%$ para $20,6 \%$, concluiu o ano com uma queda de oferta de $0,2 \%$. As exportações brasileiras de Frango obtiveram alta de $6,4 \%$, enquanto as suínas apresentaram uma contração de $11 \%$. Em relação ao consumo interno, as principais regiões metropolitanas apresentaram taxa média anual de $9,6 \%$, considerada alta em relação à média histórica (2000/2009) de 4,3\%.

As expectativas para os anos subsequentes são favoráveis. $O$ crescimento mundial vem apresentando retornos após o período de crise, isto reflete de maneira positiva no setor. 


\subsection{Modelo CAPM: Empresas Frigoríficas}

Utilizou-se o modelo CAPM para análise de retorno de capital de duas $S$. As. - pertencentes ao ramo de frigorífico. As firmas analisadas foram: JBS S.A. e BRF - BRASIL FOODS S.A., no período relativo ao ano de 2009 e 2010. O índice do mercado utilizado para esta análise foi a taxa média de crescimento do lbovespa, no mesmo período, e a taxa de retorno sem risco foi definida pela taxa Selic, vigente nos períodos de dezembro de 2009 e dezembro de 2010.

Sendo o modelo CAPM definido por:

$$
R_{j}=R_{f}+\beta\left(R_{m}-R_{f}\right)(34)
$$

Primeiramente, é necessário determinar a medida de volatilidade anual $(\beta)$, conhecida como coeficiente Beta, das empresas JBS S.A. e BRF - BRASIL FOODS S.A. e, partir disso, definir o beta do setor. Esta medida referente ao setor será definida pela média das medidas das empresas individuais analisadas. A tabela abaixo apresenta os betas individuais das firmas e sua média, que utilizaremos como medida referente ao setor frigorífico.

\begin{tabular}{|c|c|c|c|}
\hline Medida de & JBS & BRASIL & SETOR \\
\hline Volatilidade & S.A.(\%) & FOODS & FRIGORÍFICO. \\
\hline Anualizada & & S.A.(\%) & (\%) \\
\hline$\beta_{d}{ }^{*}$ & 52,59 & 30,79 & 41,69 \\
\hline
\end{tabular}

O beta da empresa também é afetado pelo seu índice de endividamento e pelos impostos incidentes sobre o lucro. Quanto maior for o índice endividamento, maior será o seu beta correspondente. Duas firmas idênticas, porém, com endividamentos diferentes, possuirão betas diferentes. Assim, para analisarmos as duas empresas, é necessário alavancar os betas, isto é, introduzir nas medidas de volatilidade os efeitos dos endividamentos financeiros para daí podermos efetivamente compará-las. Isto é feito através da fórmula:

$$
\beta_{e}=\beta_{d}\left[1+\left(1-I_{l}\right) \frac{D}{P L}\right]
$$


Onde $\beta_{d}$ é a medida de volatilidade desalavancada do setor; $\beta_{e}$ é o beta da empresa alavancado; $I_{l}$ é a soma das alíquotas de todos os impostos incidentes sobre o lucro - no Brasil é igual a 0,34. Por fim, $\frac{D}{P L}$ é o índice de endividamento utilizado, de forma que $D$ é o endividamento financeiro e $P L$ são o patrimônio líquido, ambos do período analisado. Assim, calculando os índices de endividamento e os betas alavancados têm-se:

Tabela 3: Índices de endividamentos e betas alavancados

\begin{tabular}{ccccc}
\hline & JBS & JBS S.A. & BRF- & BRF - \\
& S.A.(consolida & $\mathbf{( 2 0 1 0 )}$ & BRASIL & BRASIL \\
& do) (2009) & & FOODS & FOODS S.A. \\
& & & S.A. (2009) & $\mathbf{( 2 0 1 0 )}$ \\
\hline$\beta_{e}$ & 0,624188 & 0,645984 & 0,562238 & 0,608598 \\
D/PL* & O, 753353 & 0,832567 & 0,528209 & 0,696695 \\
$\beta_{d}$ (setor) & 0,4169 & 0,4169 & 0,4169 & 0,4169 \\
\hline
\end{tabular}

${ }^{*}$ Dados extraídos dos balanços patrimoniais 2009 e 2010 das respectivas empresas, apresentados em anexo.

Fonte: Elaborado pelo autor.

Substituindo o índice de endividamento extraído dos respectivos balanços patrimoniais na expressão (35), definem-se os betas alavancados para o período de 2009 e 2010 :

$$
\begin{gathered}
\beta_{J B S 2009}=0,4169[1+(0,66 \times 0,753353)]=0,624188 \\
\beta_{J B S 2010}=0,4169[1+(0,66 \times 0,832567)]=0,645984 \\
\beta_{B R F 2009}=0,4169[1+(0,66 \times 0,528209)]=0,562238 \\
\beta_{B R F 2010}=0,4169[1+(0,66 \times 0,696695)]=0,608598
\end{gathered}
$$

Com os betas alavancados, pode-se, agora, analisar as empresas de forma comparativa. Dessa maneira, determinam-se - através do modelo CAPM - os retornos dos ativos das empresas analisadas. Conforme dito anteriormente, utilizam-se para o índice do mercado, a taxa média de crescimento do lbovespa, no mesmo período e, a taxa de retorno sem risco foi definida pela taxa Selic, vigente nos períodos de dezembro de 2009 e dezembro de 2010. A taxa media de mercado (IBOVESPA) foi de $82,7 \%$ em 2009 e 1,0\% em 2010, dados extraídos do site da Bovespa. A taxa Selic, em dezembro de 2009 era de $8,75 \%$, e em dezembro de 2010 de $10,75 \%$, dados extraídos do site do BACEN. Assim, os retornos das empresas, calculados pelo modelo CAPM, para 2009 e 2010, foram: 


$$
\begin{aligned}
R_{J B S 2009}=R_{f} & +\beta_{e J B S 2009}\left(R_{m}-R_{f}\right)=0,0875+0,624188(0,827-0,0875) \\
= & 0,549087 \\
R_{B R F 2009}=R_{f} & +\beta_{e B R F 2009}\left(R_{m}-R_{f}\right)=0,0875+0,562238(0,827-0,0875) \\
= & 0,503275 \\
R_{J B S 2010}=R_{f} & +\beta_{\text {eJBS2010 }}\left(R_{m}-R_{f}\right)=0,1075+0,645984(0,010-0,1075) \\
= & 0,044516 \\
R_{B R F 2010}=R_{f}+ & \beta_{e B R F 2020}\left(R_{m}-R_{f}\right)=0,1075+0,608598(0,010-0,1075)= \\
0,048161 \quad(37) &
\end{aligned}
$$

Onde: $R_{J B S 2009}$ é o retorno da empresa JBS S.A. em 2009, $R_{B R F 2009}$ é o retorno da empresa BRF - BRASIL FOODS S.A. em 2009, $R_{J B S 2010}$ é o retorno da empresa JBS S.A. em 2010 e $R_{B R F 2010}$ é o retorno da BRF- BRASIL FOODS S.A. no período de 2010.

\section{CONSIDERAÇÕES FINAIS}

Com os resultados, verifica-se que ambas as firmas apresentaram, nos períodos analisados $\beta_{e}<1$, isto é, risco menor que o risco do mercado. Isto pode ser observado também a partir dos retornos esperados. No ano de 2009, ano em que o mercado apresentou um alto crescimento, as firmas analisadas visualizaram retornos esperados abaixo dos retornos do mercado. Assim como em 2010, ano em que o mercado obteve uma queda na taxa de retorno, as firmas apresentaram um declínio do retorno em uma proporção menor do que o mercado, obtendo retornos esperados superiores ao mercado.

Pode-se também observar que as duas firmas analisadas apresentaram índices de endividamento e riscos aproximadamente iguais entre si e em relação ao mercado. Indicando assim retornos de capital muito próximo, conforme verificado nos retornos esperados.

\section{REFERÊNCIAS}

BODIE, Z. MERTON, R. Finanças. Porto Alegre: Bookman, 2002.

COSTA, O. L. V.; ASSUNÇÃO, H. G. V. Análise de risco e retorno em investimentos financeiros. Barueri: Manole, 2005. 
GITMAN, L. J. Princípios de administração financeira. São Paulo: Pearson Prentice Hall, 2010.

GROPPELLI A. A.; NIKBAKHT, E. Administração financeira. São Paulo: Ed. Saraiva 2009.

HOGG R. V.;MCKEAN, J. W.; CRAIG, A. T. Introduction to mathematical statistics. Bergen County: Prentice Hall, 2004.

JORION, P. Valueat Risk - A nova fonte de referência para o Controle do Risco de Mercado. São Paulo: Editora de Cultura, 1998.

LENCIONE; Maria Angélica C. Modelos de Precificação. 2005. Disponível em: <http://www.cantareira.br/thesis2/v2n3/maria.pdf>. Acesso em: 05 set. 2014.

LINTNER, J. The Valuation of Risk Assets and the Selection of Risky Investments in Stock Portfolios and Capital Budgets. Review of Economics and Statistics.n. 47, pp. 13-37, Feb, 1965.

MARTELANC, R; PEREIRA, F.; PASIN, R. Avaliação de empresas: um guia para fusões, aquisições e gestão de valor. São Paulo: Pearson Prentice Hall, 2005.

MORETTIN, P. A.; TOLOI, C. M. Análise de Séries Temporais. São Paulo: Ed. Blucher, 2006.

MOSSIN, J. Equilibrium in a Capital Asset Market. Econometrica, n.35, pp. 768-783, Oct. 1966.

ROSS, S; WESTERFIELD, R. Fundamentos de Administração Financeira. Porto Alegre: Bookman, 1997.

ROSS, S. Probabilidade: um curso moderno com aplicações. Porto Alegre: Bookman, 2010,

SECURATO, J. R. Cálculo de tesouraria. São Paulo: Ed. Saint-Paul, 1993.

SHARPE,W.F. Capital asset prices: a theory of market equilibrium under conditions of risk. The Journal of Finance, vol.19, n.3, p.425-442, Sep., 1964.

ZHU, D., PRIETULA, M. J.; HSU, W. L. When processes learn: Steps toward crafting an intelligent organization. Information Systems Research, n. 8, v. 3, p. $302-317,1997$. 